\title{
TEACHING ESP IN THE DIGITAL WORLD - DEVELOPING A BLENDED LEARNING ENVIRONMENT FOR COMPUTER SCIENCE STUDENTS
}

\begin{abstract}
It is essential to understand that today's learner is constantly connected via a number different digital devices. Thus, technological devices should be used frequently by students and their teachers in order to provide an interaction between language learners and teachers or peer-to-peers. This study explores the challenges of developing English for Specific Purposes (ESP) courses for students of Computer Sciences and Technologies at the South East European University in the Republic of Macedonia. Based on the curriculum requirements, the ESP course has to address students' needs in today's digital world. The findings in this paper suggest that the use of different modes of delivery can create higher levels of student engagement and increase their motivation to learn English. This can happen only when digital instruction is embedded systematically in the syllabus. The paper describes the ways in which student learning can be more active and accessible in a blended learning environment. Switching back and forth between inclass and digital instruction can provide necessary hands-on experience for the students. By learning digitally, they can immerse themselves in authentic learning environments. This shift can also offer an alternative to large lecture classes enabling students to demonstrate skills and competencies that would otherwise have gone unnoticed.
\end{abstract}

Key words: blended learning environment, ESP, digital instruction, in-class instruction

\section{Introduction}

Nowadays teachers are witnessing how student learning extends outside traditional settings. The classroom itself is no longer the primary learning space. This reshaping of learning is inevitably followed by fundamental redesign of formal and informal learning spaces. The formality of the classroom is transformed by the development of digital content. Thus, the classroom turns into a collaborative learning space where the students bring in their outside learning experience and combine it with in-class learning. The technological tools used in class only enhance the transformation enabling students to work and learn as teams. Blended learning, as a new type of learning, combines in-class with out-of-class learning, allowing students to learn

\footnotetext{
* Language Centre, South East European University, Ilindenska, 335, 1200 Tetovo, North Macedonia; e-mail:d.kiroska@seeu.edu.mk
} 
anytime and everywhere. That way, the instructors can focus on what the students have learned and not only on the delivery method in class. Even though out-of-class learning has always been a learning goal for students, with the use of technology this becomes easier and learning becomes more engaging.

Outside the classroom, students tend to learn in an informal setting using interaction and collaboration. In this sense, online education can be helpful by connecting learners from various places for synchronous group discussions, collaborative projects and different hands-on learning assignments.

It is essential to understand that today's learner is constantly connected via a number different digital devices. Today's learners' lives are also greatly dependent on technology. As a result, students bring with them their experience of using technology, as well as their beliefs and perceptions that technology should play a role in their learning. Technology can shape, and reshape, who is the learner and who is the teacher. It can open up knowledge and content that otherwise would be less available.

After all, language education does not only happen in the classroom and should not stop after the learners leave the classroom. Technology is useful in most academic areas but is very important in language learning because students communicate so much through technology. Thus, technological devices should be used frequently by students and teachers in order to provide an interaction between language learners and teachers or peer-to-peers. The development of web-based language teaching and learning activities continues to be a stimulating and growing field allowing language teachers to create their own web-based language activities and use these communication tools.

In this sense, digital learning can increase flexibility of access, eliminate geographical barriers, and improve convenience of use and effectiveness of collaborative learning. Additionally, some studies also show that students are likely to perform better in an online learning environment than in a traditional classroom environment (Liu, Ho and Song 2011). Digital teaching and learning activities have continued to develop as an alternative to traditional face-to-face teaching and learning. According to Dickinson et al. (2008), if instruction takes place in a less traditional setting, learners experience a more comfortable learning environment.

As a result of this new awareness, the philosophy behind European Higher Education is being altered with university educational models that initiate new methodologies aimed at life-long learning for personal or professional purposes. Preparing students to be able to communicate successfully in the international labor market is one of the biggest challenges of university degrees, i.e. the acquisition of English written and spoken skills. Technological advancements had a significant effect on learning styles: learners use computer-mediated communication to further their written and spoken skills, although the effectiveness of these innovations greatly depends on the way they are used. 
Perhaps surprisingly, little empirical research has been published on students' common use of technology in the context of higher education in the Republic of Macedonia. Furthermore, no relevant study has been done with the students of the South East European University (SEEU) regarding their expanding preferences for both in-class learning and technological resources for learning English. This paper aims at further developing the English syllabus, especially that of English for Specific Purposes (ESP). This paper investigates the merits of technology in ESP instruction because occupational English is the focus and almost always, those skills will require proficiency with technology.

\section{Literature review}

Digital learning needs to be applied to computer-assisted language learning because it can promote collaborative learning. Language courses should be designed to promote learners' immersion in the target language and for creating opportunities with meaningful and authentic interaction. Language learners need to be equipped with the necessary tools for social and cultural exploration in the target language, with the integration of new technologies in language classes (Warschauer and Meskill 2000).

The term digital learning environment as used in this paper includes the full range of technological tools and resources used to support the learning process. Authentic digital learning environments are the spaces that are created when students collectively and consistently interact through web 2.0 tools. When this type of engagement is embedded thoroughly within the syllabus, the authentic digital learning environment takes the role of a traditional Learning Management System (LMS) and does so in a way that can lead to new learning opportunities for students.

Digital learning environments are technical solutions for supporting learning, teaching and studying activities (Suhonen 2005). According to Suhonen (2005: 43) a digital learning environment can be educational software, a digital learning tool, an online study program or a learning resource. Anohina (2005) points out that a digital learning environment may thus consist of a combination of different technical solutions; a digital learning environment may thus be used as the basis for an e-learning program. The development of effective digital learning environments is not a simple task. Digital learning done outside the classroom may be a cost-effective and flexible alternative to classroom learning, but if not executed appropriately it may be a waste of time and money as well. The challenge when developing such a learning environment is to use technology skillfully and creatively to solve problems and meet the needs that arise in various learning contexts (Kähkönen et al. 2003). The best designed methods are those that help designers to develop innovative and effective solutions by clearly depicting 
the most important procedures and aspects of the development process (Design-Based Research Collective 2003).

Some researchers have indicated that the most preferred form of training delivery is still face-to-face. Nevertheless, others (Beare 1989; McCleary and Egan 1989) have concluded that the outcomes from digital learning are similar to those from traditional classroom settings.

Results from Bernard et al. (2004: 379-439) and other reviews of the distance education literature (Cavanaugh 2001) point to no significant differences in effectiveness between distance education and face-to-face education, suggesting that distance education, when it is the only option available, can successfully replace face-to-face instruction. Moreover, they suggested that "good" distance education applications and "good" classroom instruction should be relatively equal to one another, regardless of the media used, especially if the media are used simply for the delivery of content.

Lam (2009) and Olson and Wisher (2002) in their studies argue that the effectiveness of web-based instruction over the classroom-based variant depends on the level of control students have over their learning, that is, the level of their learner autonomy and the type of knowledge faculty is providing the students with. Therefore, web-based courses that included procedural knowledge and problem solving were the most effective. Similarly, Schaber et al. (2010) and Young, Klemz, and Murphy (2003) suggested that web-based instruction was superior to classroom-based instruction when the course in question included course management software that the students used consistently and when project-oriented materials were part of the instruction. In summary, the arguments from these studies suggest that web-based instruction is more effective than classroom-based instruction when students are in control of their learning and procedural knowledge is taught. However, student performance is a combination of technology, students' control of learning and their learning objectives, and not because of the web-based instruction per se.

Arsham (2015) points out that online courses do not diminish the connection between the students and the instructor, although this is believed to be the case. On the contrary, online learning provides numerous possibilities for creating a personalized and highly effective learning environment. Melville (2005) points out that today's students have different preferences for how information is presented. Their preferences are based on their experience with technology. In addition, Marzano et al. (2001) suggest using different technological tools with different learning strategies such as: summarizing, note taking, homework and practice, collaborative learning, setting objectives, providing feedback, and generating questions.

Technology has been utilized in ESP instruction since the introduction of the computer into the classroom, throughout the development of the Internet and the World 
Wide Web and to the very invention of mobile and cloud-computing technologies. According to Bloch (2013), technology in ESP teaching has provided access to authentic texts and has been used as a tool for helping with the traditional (face-toface) type of language learning. According to Arnó-Macía (2012), the relationship between information technology and ESP is still under the influence of computerassisted language learning (CALL) together with the newest developments in language teaching and applied linguistics. As ESP classrooms welcomed technology, instructors started using interactive multimedia, web-based resources, the Internet and a range of different technological tools in order to promote student learning and connect that learning to pertinent situations. Technology also offers various visualization tools that can be used in language learning (Krajka 2015). When it comes to ESP instruction, these tools can be utilized for content and topic visualization as well as for vocabulary learning.

According to Bloch (2013), another key problem that has to be researched more is how to put into practice new technologies that are continually being introduced. He believes that the choice of the most suitable technology in the ESP classroom depends on various factors, the most important of them being the problem the teacher wants to address and the learning objective that needs to be accomplished, which in numerous cases involves a belief that learning to use the technology itself can fulfill the needs of the learner.

Summing up the previous studies, one can conclude that the research on technology and ESP instruction is still in its early stages. There are a number of topics and technologies that haven't been adequately researched. More needs to be done, specifically innovative and inventive applications need to be further investigated and examined. Additionally, taking the specific nature of ESP into consideration, it can be concluded that the use of technology in ESP instruction should be based on students' preferences, requirements and learning styles.

\section{The academic context}

South East European University is a private-public, nonprofit higher education institution, consisting of faculties, centers and institutes. SEEU has five faculties: the Faculty of Contemporary Sciences and Technologies, the Faculty of Languages, Culture and Communication, the Faculty of Law, the Faculty of Contemporary Social Sciences and the Faculty of Business and Economics

The Language Center (LC) was founded in 2001 and it was the first independent unit to provide instruction within SEEU. The primary function of the LC is to provide courses specified in the curricula of the five SEEU faculties. Basic Skills English (BSE) 
is the largest of the Center's teaching programs. It provides language courses from A1 to $\mathrm{C} 1$ levels to all first-year students at the University. According to the university three-year study cycle, all the students are required to take a minimum two semesters of BSE. Students from all SEEU faculties are required to complete English language courses specialized to their field (ESP) during the third and the fourth semester.

This part of the paper provides an overview of the syllabi offered to the students that study at the Faculty of Contemporary Sciences and Technology, study program of Computer Sciences. According to the syllabus for ESP 1 offered in the third semester, by the end of the course students will be able to evaluate a website, participate in a discussion forum on Google Classroom, use lexis related to computer science, distinguish between a subjective and objective point of view, express and defend a specific point of view and communicate freely about burning issues in the field of computer science and information technology. Google Classroom (GC) is used as the main course management system, providing a ground for creating and implementing a blended learning environment.

Upon successful completion of the ESP 2 course offered in the fourth semester, the students will be able to use the language they acquire and practice throughout the course, integrating the four main language elements towards fulfilling their academic needs as well as their occupational needs for their future careers. Thus, they will know how to job hunt (write CVs, cover letters, participate in mock job interviews), think critically, appreciate opposing points of view and evaluate and provide constructive feedback to their peers on a piece of writing and spoken performance in interviews and debates.

The assessment is performed through various assessment criteria, such as: evaluating a website, in-class presentations, writing blogs, CVs/Cover letters, mock job interviews, creating video presentations and quizzes on Google Classroom. The classes are divided between in-class time and homework assignments done on GC.

The use of GC is the integral part of students' grading criteria. The ESP courses have classes on GC and different tasks are assigned throughout the semesters. Students can use Google Classroom during class time, or they can complete their assignments outside the classroom. So far, and based on students' opinions, GC has proven to be a powerful tool in enhancing student learning outside the classroom, thus increasing their autonomous learning.

Students need not only a vast choice of materials; they also need to engage in quality activities. The resources used should be meaningful and have a purpose that learners understand. The tools and resources that technology provides expose students to a greater authenticity and improve their English skills. To provide authentic experiences, teachers at schools together with the students must plan activities that 
can meet a variety of knowledge levels, learning styles and life experiences. This is a valuable strength of the model for the students but could be a weakness for the teacher. It may be difficult even overwhelming to access adequate resources.

Below is a representation of some of the teaching tools that have been used in the ESP classes described in this paper. The tools cover a variety of learning materials that can be utilized both in a face-to-face and an online environment. Further below, a short description of some of the tools will be given.

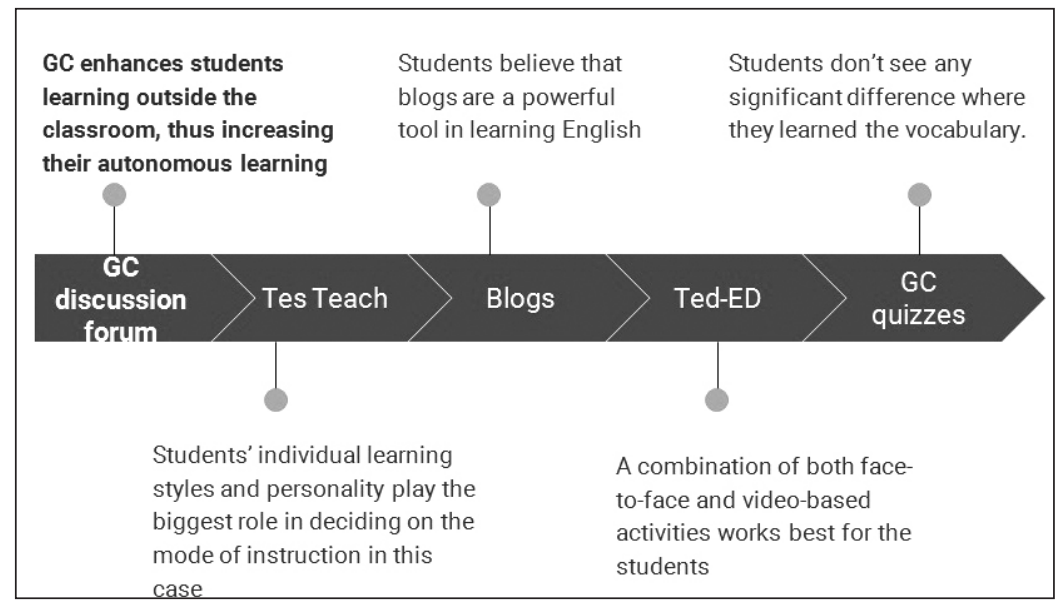

Figure 1. Blended learning tools

This paper identifies student perceptions about the strengths and weaknesses of the face-to-face learning and digital learning. The purpose of the paper is not only to show how the instructor applies technology in the instruction of ESP, but also to examine students' understanding of both modes of language learning and which one suits them better. The paper aimed to validate the fact that students need to self-select appropriate learning environment based on their own learning preferences. Only then will the learning be effective and successful.

\subsection{Discussion forum on GC}

Some researchers (Bensoussan et al. 2006) indicate that the use of online discussion forums in ESP instruction enhances students' participation, interaction, and communication quality. This study suggests that the forum created a motivating environment for students to participate in language learning and discussions. In general, the use of the forum had benefits for learning and students had positive attitudes towards it. The next picture shows how the discussion forum thread looked: 
Daniela Kirovska-Simjanoska

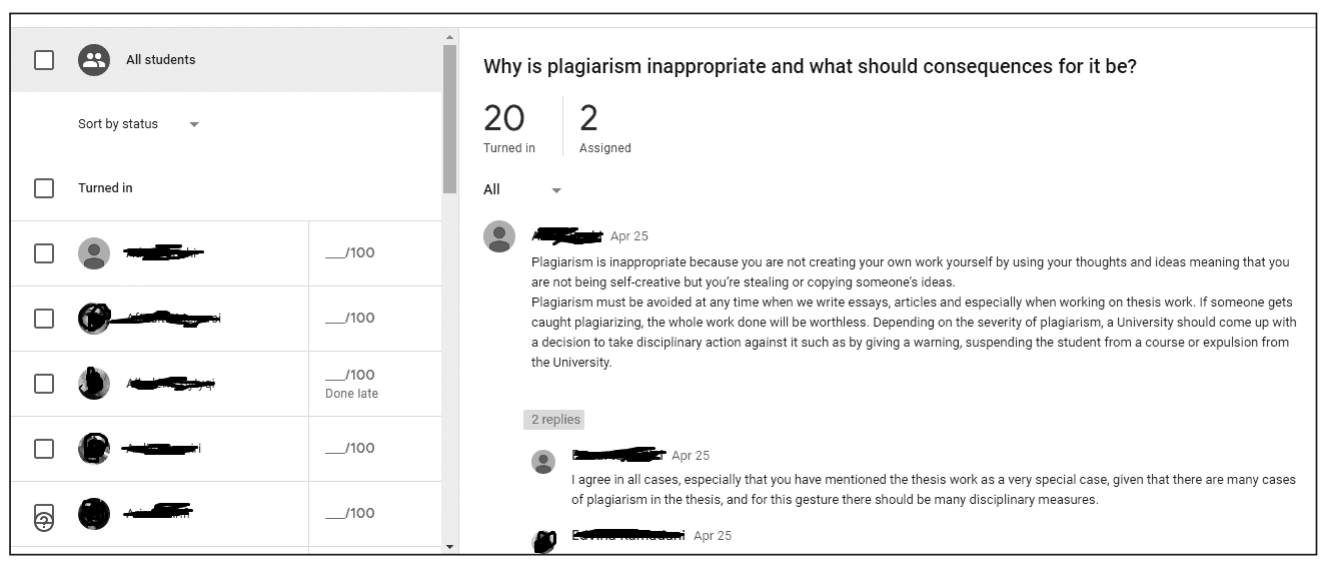

Figure 2. Discussion forum thread

Students believed that the digital learning environment would lack social interaction and would be impersonal. They didn't regard discussion forums as equivalent to class discussions. However, after being exposed to learning in a digital environment, students changed their perception. The change occurred because the instructor made sure that her online presence corresponded to the class presence, making the digital learning environment as interactive as possible. Students realized that they could "talk" to the instructor and other students in an online environment, perhaps in a way similar to a chat on Facebook. Not only students, but also instructors, should realize that social interaction means something quite different today than ten years ago.

\subsection{Combination of reading and video lessons in a digital environment}

The Internet is the defining technology for reading, writing and communication of the $21^{\text {st }}$ century. However, without the ability to find the information in an efficient and effective manner, students' access to information will be limited. The teachers need to equip students with necessary critical thinking skills, analyzing and synthesizing information skills in order to assist them in becoming good readers in the web-based environment. As Leu (1997: 65) points out, "individuals unable to keep up with the information strategies generated by the new information technologies will quickly be left behind."

Videos are very powerful tools in helping English language learners improve and further develop their language skills. They provide the learner with content, context, and language. Videos present information and ideas in a dynamic and 
interactive way. Videos can be an accessible and engaging substitute for a face-to-face learning environment. This will work provided that teachers offer support and make sure that the learner's role is not a passive one.

Below is a tool that combines the uses of both videos and reading texts.

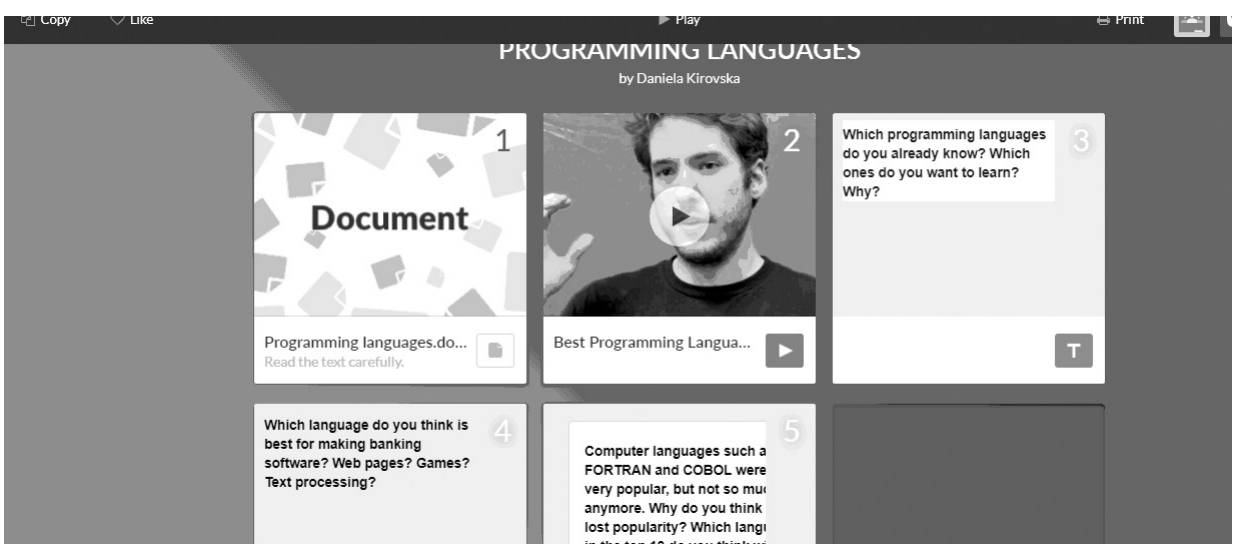

Figure 3. Tes Teach (https://www.tes.com/lessons)

\subsection{Blogs}

In this particular ESP course, blogs were assigned as a task done outside the classroom. They were individual blogs written in WordPress, a popular platform used for blogging. Students had different topics for their entry blogs. Here is one short example of a blog entry about their experience at the University:

\section{A DAY IN LIFE OF A CST STUDENT AT SEEU}

\footnotetext{
$\therefore$ E Uncategorized (1) January 13, 2019 झा Minute

As a student in the Faculty of Computer Science and Technology (SEEU) the routine of my day isn't so easy. My day usually starts at 8 o'clock, I wake up, get ready for the school and here I am taking lessons for subjects I like but there are few i don't prefer much.Hours run away quickly when I have to study for things i like more.But when I have to listen lessons for subjects I don't like it's different, for example I don't like Tuesday because I have lessons for subjects I don't like, so Tuesday it looks like having 48 hours. Most of all $\mathrm{i}$ like hours of practice because we are all more activated and I thing when you practice the theory of something you learn,you keep that thing longer in your memory. That's why practice without theory is more valuable than a theory without practice
}

Figure 4. A blog post 
When asked, at the end of the semester, if the instructor should keep blog writing in the syllabus as part of the grading criteria, all of the students answered with yes. This is an indicator of their satisfaction with blogging. The instructor was aware of the enthusiasm because the students expressed genuine interest when told about the blog writing. The entries were shared and there was an in-class discussion on the writing. This proved to be appealing to the students because they were competing for the best written blog. The blog with the most striking design was also chosen. This was easily noticed as the instructor moved around the classroom and observed students' reactions.

\subsection{Quizzes on GC}

Students can learn vocabulary on their phones while they are on the go. The convenience of mobile phones combined with the Internet enables them to study wherever they want. They can watch videos, revise vocabulary using different apps and all of this adds to their learning experiences. However, for all of this to be effective and successful, there is the need for constant feedback from the teacher. The students reported that they weren't always sure if they (had) learnt the correct words. They needed an official assessment in a quiz form that would increase their self-confidence.

In summary, the students' comments indicated that the best environment for learning vocabulary would be a combination of both environments, for instance using smartphones in class for definitions or explanations. Watching interactive videos also worked better in class, due to the instant follow-up that such activities have. Students need additional training in using phones as educational tools. Phones can be powerful tools used in the classroom, but students don't fully realize their value and potential

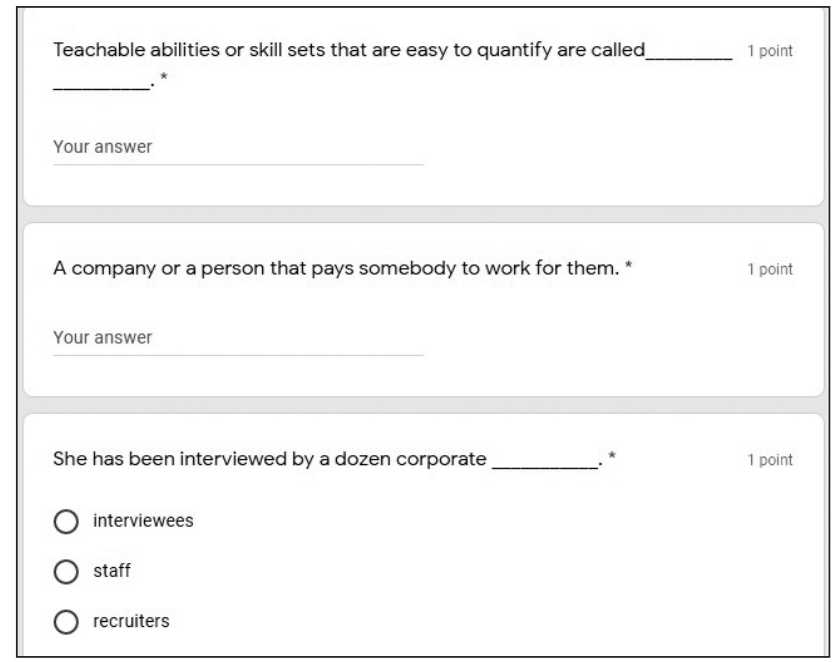

Figure 5. GC quiz 


\section{The students' experience}

Towards the end of the semester students' evaluations are administered throughout the faculties and centers. The evaluations are made online through GC and include 16 statements that cover the materials used in class, the course content, the instructor's role and the students' role as well. The students tick the answers to questions 1-14 that best reflect their opinion on a Lickert scale from Strongly agree (SA), Agree (A), Neutral (N), Disagree (D) to Strongly disagree (SD). Students respond to questions 15-16 by using a 5-point scale, from excellent (5) to poor (1).

This activity is managed through the University's e-Learning Center and it is completely anonymous. The aim is to provide information about the course and the instructor and possible areas for improvement.

Below is the students' course evaluation for the ESP 1 in the academic 2017/18.

English for specific purposes I (CST BI)

\begin{tabular}{|c|l|}
\hline 1 & The course materials helped me understand the subject matter \\
\hline 2 & The work required of me was appropriate based on course objectives \\
\hline 3 & The assessment appropriately reflected the syllabus \\
\hline 4 & The course encouraged me to think critically \\
\hline 5 & The course provided opportunities for practical application of the knowledge \\
\hline 6 & I learned a great deal in this course \\
\hline 7 & My class presence in this course was regular \\
\hline 8 & The instructor provided clear expectations for the course \\
\hline 9 & The instructor communicated effectively \\
\hline 10 & The instructor stimulated my interest in the subject matter \\
\hline 11 & The instructor provided useful feedback on my work \\
\hline 12 & The instructor used variety of teaching methods \\
\hline 13 & The instructor demonstrated mastery of the subject matter \\
\hline 14 & The instructor's class attendance was regular \\
\hline 15 & Overall course content rating \\
\hline 16 & Overall instructor rating \\
\hline
\end{tabular}

\begin{tabular}{|c|c|c|c|c|c|c|c|c|c|c|c|c|c|c|c|}
\hline 1 & & & 1 & 6 & 7 & & $0 \%$ & $0 \%$ & $0 \%$ & $14 \%$ & $86 \%$ & 4.86 & 4.27 & 4.44 \\
\hline 2 & & & & 7 & 7 & & $0 \%$ & $0 \%$ & $0 \%$ & $0 \%$ & $100 \%$ & 5.00 & 4.45 & 4.53 \\
\hline 3 & & & 1 & 6 & 7 & & $0 \%$ & $0 \%$ & $0 \%$ & $14 \%$ & $86 \%$ & 4.86 & 4.51 & 4.58 \\
\hline 4 & & 2 & & 5 & 7 & & $0 \%$ & $0 \%$ & $29 \%$ & $0 \%$ & $71 \%$ & 4.43 & 4.13 & 4.03 \\
\hline 5 & & & 2 & 5 & 7 & & $0 \%$ & $0 \%$ & $0 \%$ & $29 \%$ & $71 \%$ & 4.71 & 4.28 & 4.32 \\
\hline 6 & & 1 & & 6 & 7 & & $0 \%$ & $0 \%$ & $14 \%$ & $0 \%$ & $86 \%$ & 4.71 & 4.26 & 4.35 \\
\hline 7 & & & & 7 & 7 & & $0 \%$ & $0 \%$ & $0 \%$ & $0 \%$ & $100 \%$ & 5.00 & 4.67 & 4.72 \\
\hline 8 & & & & 7 & 7 & & $0 \%$ & $0 \%$ & $0 \%$ & $0 \%$ & $100 \%$ & 5.00 & 4.45 & 4.54 \\
\hline
\end{tabular}


Daniela Kirovska-Simjanoska

\begin{tabular}{|c|l|l|l|l|l|l|l|l|l|l|l|l|l|l|l|l|}
\hline 9 & & & & 7 & 7 & & $0 \%$ & $0 \%$ & $0 \%$ & $0 \%$ & $100 \%$ & 5.00 & 4.56 & 4.56 \\
\hline 10 & & & 1 & 6 & 7 & & $0 \%$ & $0 \%$ & $0 \%$ & $14 \%$ & $86 \%$ & 4.86 & 4.30 & 4.35 \\
\hline 11 & & & 1 & 6 & 7 & & $0 \%$ & $0 \%$ & $0 \%$ & $14 \%$ & $86 \%$ & 4.86 & 4.39 & 4.45 \\
\hline 12 & & & & 7 & 7 & & $0 \%$ & $0 \%$ & $0 \%$ & $0 \%$ & $100 \%$ & 5.00 & 4.17 & 4.33 \\
\hline 13 & & & & 7 & 7 & & $0 \%$ & $0 \%$ & $0 \%$ & $0 \%$ & $100 \%$ & 5.00 & 4.54 & 4.57 \\
\hline 14 & & & & 7 & 7 & & $0 \%$ & $0 \%$ & $0 \%$ & $0 \%$ & $100 \%$ & 5.00 & 4.77 & 4.82 \\
\hline 15 & & & 1 & 6 & 7 & & $0 \%$ & $0 \%$ & $0 \%$ & $14 \%$ & $86 \%$ & 4.86 & 4.44 & 4.49 \\
\hline 16 & & & & 7 & 7 & & $0 \%$ & $0 \%$ & $0 \%$ & $0 \%$ & $100 \%$ & 5.00 & 4.51 & 4.56 \\
\hline
\end{tabular}

Figure 6. Students' course evaluation

The first row represents the individual average grade, the middle row shows the faculty's (center's) average grade and the last row represents the SEEU average grade.

Based on the individual average grades, it can be concluded that the students considered this ESP course particularly valuable. The blended learning environment proved an efficient way of learning the course content. This course used online technology not just to supplement, but also to transform and improve the learning process.

\section{Recommendations for the future}

This paper recognizes the value and the potential of technology and the way it is reshaping the educational landscape. Based on the course outcomes and students' opinions, it makes the following recommendations:

- Instructors - instructors should provide the best learning environment for their students. With many different technological tools at hand, the classroom learning should and must be extended to and moved into the outside world. They also need to find a way to teach students the skills they need to become more selfregulated and autonomous learners. This is where the course syllabus intertwines with the faculty curricula in establishing a set of digital skills necessary for the students to fully function in the outside world. It is very reasonable to suggest that a blended model combining self-study in a digital environment (online) with face-to-face instruction would be one of the best choices for ESP. In a world where technology is widely accessible, the teaching and learning process need to be reshaped and redefined.

Instructors need to: embed the use of some of the technological tools they are familiar with in their ESP courses; provide students' with various literature and support material; encourage students in making effective use of the 
technological tools; integrate various online activities and Open Educational Resources (OER); encourage students to self-explore and develop their critical thinking skills.

- Students - students should make greater use of a variety of learning materials; they must actively ask for support from academic and professional staff in using different technological tools for learning. They should actively seek a diverse range of materials and activities that will reflect their immediate needs for learning English.

\section{Conclusion}

This paper tries to identify students' preferred ways of learning, thus adding evidence and providing guidance for decisions about what is best done online and what works best in a face-to-face environment. The preference is mainly connected to their learning styles and the types of assignments provided. However, students still highly value the presence of the teacher in the classroom and the social interaction that instruction in-person provides. They value the whole experience of being at a university, not just attending classes. Also, digital tools cannot simply be transferred from one learning environment to the other automatically. In order for their use to be successful they need to be adapted and modified according to students' needs.

Learning in a digital environment can be successful only when it contains stimulating and motivational tasks. Assignments should be carefully planned and chosen to stimulate students' needs for learning. The digital tools that they use in their everyday lives (mobile apps, social media, even games) can be transformed into learning tools, but only when they are systematically embedded in the syllabus. This can increase students' engagement and enhance their motivation for learning.

In summary, ESP learning can be enhanced by the use of digital devices. Due to technology, ideas and individuals can connect and collaborate anytime, anywhere. Failing to recognize that simple fact is failure on the part of the instructor and the institution. The goal of the ESP instructor in the classroom should be to fully maximize the potential of mobile phones and teach students how to take advantage of their digital devices. These devices can be used to support the dialog between instructors and learners, thus reducing the advantage that face-to-face instruction has with having teachers present in class. This can be done as simply as using tools that provide immediate feedback, such as by taking a quick and live poll of students' opinions, or engaging students in discussion forums on Google Classroom, using phones for doing quick class research and by using various communication platforms to offer personal tutoring to students worldwide. Students have infinite access to information 
but not enough knowledge and skills to use that information. This is where learning opportunities in the digital environment find their biggest potential.

Switching back and forth between in-class and digital instruction can provide the necessary hands-on experience for the students. By learning digitally, they can immerse themselves in authentic learning environments. This shift can also offer an alternative to large lecture classes enabling students to demonstrate skills and competencies that would otherwise have gone unnoticed. The study describes the ways in which students' learning can be more active and accessible through the use of a digital environment.

Instructors need to realize that simply transferring lectures into a digital environment does not necessarily mean effective and efficient learning. The challenge is to systematically embed both modes of delivery by identifying the values of faceto-face instruction and digital instruction. They should also be able to recognize what teaching is more convenient for the students and can be done better in a different environment. Finally, they should be able to combine the two modes of delivery in order to get better learning outcomes.

When it comes to decisions about the mode of delivery, policy makers, instructors, and everyone involved in higher education should focus on the question of the appropriateness, namely, when it is most appropriate to use face-to-face, digital or combined learning. Instructors who are in favor of planning the learning far in advance and controlling the course content by using digital tools will be attracted by the digital environment. Those who, on the other hand, appreciate the social interaction in class more, will opt for the face-to-face environment. A suitable learning environment-can be more challenging to students, engaging them interactivity in collaborative learning and enhancing their learner autonomy at the same time.

Technology as a new and evolving practice shows numerous potential benefits for students. In situations where the English language is only learnt and practiced in a face-to-face environment, digital instruction can be used as an alternative setting. By providing more challenging and motivating activities, enhancing and promoting learner autonomy and life-long learning, students can learn at their own pace. Thus, the digital learning environment can be used to make students' learning experiences more substantial, appealing and lasting.

\section{References}

Anohina, A. (2005). Analysis of the terminology used in the field of virtual learning. Journal of Educational Technology and Society, 8(3), 91-102. 
Arnó-Macía, E. (2012). The role of technology in teaching languages for specific purposes. Modern Language Journal, 96 (Focus Issue), 89-104.

Arsham, H. (2015) Interactive Education: Impact of the Internet on Learning and Teaching. (15 May 2017) <http://home.ubalt.edu/ntsbarsh/interactive. htm\#rapessv>.

Beare, P. L. (1989). The comparative effectiveness of videotape, audiotape, and telelecture in delivering continuing teacher education. The American Journal of Distance Education, 3(2), 57-66.

Bensoussan, M. et al. (2006). CMC among multilingual students of English for academic purposes: linguistic and sociolinguistic communicative factors in online written responses. Language@ Internet, 3. (10 September 2016)<http:// www.languageatinternet.org/articles/2006/370>.

Bernard, R. M. et al. (2004). How does distance education compare with classroom instruction? A meta-analysis of the empirical literature. Review of Educational Research, 74(3), 379-439. (15 July, 2017) <http://journals.sagepub.com/doi/ pdf/10.3102/00346543074003379>.

Bloch, J. (2013). Technology and ESP. In: B. Paltridge and S. Starfield, The Handbook of English for Specific Purposes, Chichester: Wiley-Blackwell, 429-447.

Cavanaugh, C. S. (2001). The effectiveness of interactive distance education technologies in K12 learning: A meta-analysis. International Journal of Educational Telecommunications, 7(1), 73-88. (08 April 2017) <http://www. unf.edu/ ccavanau/CavanaughIJET01.pdf $>$.

Design-Based Research Collective. (2003). Design-based research: An emerging paradigm for educational inquiry. Educational Researcher, 32(1), 5-8.

Dickinson, M. et al. (2008). A balancing act: how can intelligent computer-generated feedback be provided in learner-to-learner interactions? Computer Assisted Language Learning, 21(4), 369-382.

Krajka, J. (2015). Needs analysis in planning ESP courses: On the role of information and communication technologies. In: M. Sowa, M. Mocarz-Kleindienst and U. Czyżewska (eds.), Teaching Foreign Languages to Meet the Needs of the Labour Market, Lublin: Wydawnictwo KUL, 221-237.

Kähkönen, E., V. Rossano and M. Tedre (2003). Approaches and methodologies for a culturally contextualized educational technology. In: E. Kähkönen (ed.), Proceedings of the $2^{\text {nd }}$ International Conference on Educational Technology in Cultural Context, Joensuu, Finland: University of Joensuu, 5-10.

Lam, M. (2009). Effectiveness of web-based courses on technical learning. Journal of Education for Business, July/August, 323-331. 
Leu, D. J., Jr. and D. D. Leu (1997). Teaching with the Internet: Lessons from the classroom. Norwood, MA: Christopher-Gordon.

Liu, E. Z. F., H. C. Ho and Y. J. Song (2011). Effects of an online rational emotive curriculum on primary school students' tendencies for online and real-world aggression. Turkish Online Journal of Educational Technology, 10(3), 83-93.

Marzano, R., D. Pickering and J. Pollock (2001). Integrating Technology into the Classroom Using Instructional Strategies. (15 June 2015) <http://www.tltguide. ccsd.k12.co.us/instructionaltools/strategies/strategies.html>.

McCleary, I. D. and M. W. Egan (1989). Program design and evaluation: Two-way interactive television. The American Journal of Distance Education, 3(1), 5060.

Melville, E. (2005). Technology Integration Strategies. Teaching Today. (25 April 2015)< http://www.glencoe.com/sec/teachingtoday/subject/tech_integration.pml>.

Olson, T. M. and R. A. Wisher. (2002). The effectiveness of web-based instruction: An initial inquiry. International Review of Research in Open and Distance Learning, 3(2) (online). (06 April 2016) <http://www.irrodl.org/index.php/ irrodl/article/view/103/182>.

Schaber, P. et al. (2010). Designing learning environments to foster affective learning: Comparison of classroom to blended learning. International Journal for the Scholarship of Teaching and Learning, 4(2), 1-18.

Suhonen, J. (2005). A Formative Development Method for Digital Learning Environments in Sparse Learning Communities. Unpublished Doctoral Dissertation. Department of Computer Science, University of Joensuu, Finland. (05 April 2016) <http://joypub.joensuu.fi/publications/dissertations/suhonen learning/suhonen.pdf $>$.

Warschauer, M. and C. Meskill (2000). Technology and second language teaching and learning. (10 June 2015) < http://education.uci.edu/markw-tslt.html $>$.

Young, M. R., B. R. Klemz and J. W. Murphy (2003). Enhancing learning outcomes: The effects of instructional technology, learning styles, instructional methods, and student behavior. Journal of Marketing Education, 25(2), 130-142. 